Encontros Bibli: revista eletrônica de biblioteconomia e ciência da informação, $v .17, n$. esp. 2 - III SBBC, p.65-81, 2012. ISSN 1518-2924. DOI:10.5007/15182924.2012v17nesp2p65

\title{
A INFLUÊNCIA DO OPEN ACCESS NAS COMUNIDADES ACADÊMICAS DA ÁREA DE BIBLIOTECONOMIA NO NORDESTE DO BRASIL
}

\author{
Virgínia Bárbara Aguiar Alves ${ }^{\mathrm{i}}$
}

\begin{abstract}
Resumo: Verifica a influência do Open Access (OA) nas comunidades acadêmicas da área de biblioteconomia das Universidades Federais da Região Nordeste do Brasil. Tem como objetivo geral identificar e discutir a influência do movimento OA. A metodologia adotada consiste na combinação da abordagem qualitativa e quantitativa; os instrumentos de coleta de dados utilizados foram questionários e entrevista. A entrevista foi aplicada ao tecnólogo sênior do Instituto Brasileiro de Informação, Ciência e Tecnologia (IBICT) com a finalidade de obter informações sobre o movimento OA no Brasil. Os questionários aplicados aos professores e alunos dos cursos de Biblioteconomia com a finalidade de verificar os efeitos e as consequências do movimento OA sobre essas comunidades. Os resultados dos inquéritos apontam vários indicadores positivos da influência do movimento OA sobre essas comunidades acadêmicas, entre os quais podemos citar: a existência de repositórios institucionais (RI) em Universidades Federais Nordestinas, um alto percentual de utilização de repositórios institucionais, o elevado percentual de utilização e produção de publicações bibliográficas em OA. Também, o conhecimento e a concordância com o movimento OA demonstram o impacto desse movimento nas comunidades acadêmicas da Região Nordeste do Brasil.
\end{abstract}

Palavras-chave: Acesso livre. Acesso livre - Região Nordeste do Brasil.

\section{THE INFLUENCE OF OPEN ACCESS ON LIBRARY SCIENCE ACADEMIC} COMMUNITIES IN NORTHEASTERN BRAZIL

Abstract: This article verifies the influence of the Open Access (OA) on the academic communities of Librarianship in the Federal Universities in the Northeastern Region of Brazil. Its global goal is to identify and discuss the influence of the OA movement. The adopted methodology consists of the combination of the qualitative and quantitative approaches; surveys and interviews were used as data collection instruments. The interview was applied to the senior technologist of the Brazilian Institute of Information Science and Technology (IBICT-Instituto Brasileiro de Informação em Ciência e Tecnologia) aiming to obtain information on the OA movement in Brazil. The surveys applied to teachers and students of the Librarianship courses, aiming to verify the effects and consequences of the OA movement on those communities. The survey outcomes point out to several positive indicators of the OA movement influence on those academic communities among which we can include: the existence of institutional repositories in Northeastern Federal Universities, the high percentage of use of institutional repositories, the high percentage of use and production of bibliographic publications with $O A$. Also, the knowledge and concordance with OA movement show the impact of this movement on the academic communities in the Northeastern Region of Brazil.

Keywords: Open Acces. Open Access - Northeastern Region of Brazil

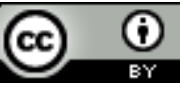

Esta obra está licenciada sob uma Licença Creative Commons

${ }^{\mathrm{i}}$ Universidade Federal de Alagoas. virginiabarbara@ua.pt 65 


\section{INTRODUÇÃO}

A procura da informação e a sua disseminação atravessaram gerações e, entre o final do século XX e o início do século XXI, surgiu o movimento do Open Access (OA), um modelo alternativo para a comunicação científica, que vem contribuindo para a consolidação desse sonho. O modelo estabeleceu padrões para a interoperabilidade entre bibliotecas digitais e repositórios temáticos e institucionais, desencadeando uma verdadeira rede de eventos, com o objetivo de apoiar o movimento para o acesso aberto ao conhecimento científico.

Exemplos do impacto do modelo implementado são:

- A Declaração Sobre a Ciência no Século XXI (1999);

- A Budapest Open Access Initiative (2002);

- A Bethesda Statement on Open Access Publishing (2003);

- A Berlin Declaration on Open Access to Knowledge in Sciencies \& Humanities (2003);

- A International Federation of Library Associations and Institutions (IFLA) on Open Access for Scholarly Literature (2003);

- A Declaração de Salvador para Acesso Aberto (2005);

- O Manifesto Brasileiro de Apoio ao Acesso Livre à Informação Científica em 2005.

Esta pesquisa insere-se na área da Ciência da Informação e a temática compreende questões relativas à comunicação científica e, de uma forma específica, ao Movimento do Acesso Livre. O estudo pretende, concomitantemente, identificar e discutir a influência do movimento OA nas comunidades acadêmicas da área de Biblioteconomia nas Universidades Federais da Região Nordeste do Brasil.

O movimento do acesso livre vem procurando tornar possível a comunicação científica entre milhares de pesquisadores espalhados pelo mundo, quebrando assim as barreiras geográficas e facilitando a disseminação da literatura científica, constituindo-se como meio essencial para a construção do conhecimento, que compreende a produção, a comunicação (disseminação do conhecimento) e a aplicação do conhecimento gerado na criação de novos conceitos. 


\section{OBJETIVOS E METODOLOGIA}

Sendo esta uma pesquisa exploratória, tenderá a assumir a forma de pesquisa bibliográfica que foi desenvolvida com base em material já elaborado e constituído, principalmente, de livros e artigos científicos.

Trata-se de uma investigação descritiva - que consiste em estudar, compreender e explicar a situação do objeto de investigação - inclui coleta de dados para testar a hipótese e responder às questões que lhe digam respeito. A descrição das informações foi rigorosa, resultando diretamente dos dados recolhidos, como a transcrição de entrevistas, cujas notas foram analisadas posteriormente. Os dados recolhidos respeitaram a forma segundo a qual estes foram registrados, na tentativa de analisar e encontrar a melhor resposta para a questão de investigação. Nesse contexto, a utilização da abordagem qualitativa e da abordagem quantitativa revela diferentes aspectos da realidade empírica envolvida na pesquisa, pois o fato de utilizar diferentes métodos permite uma melhor compreensão dos fenômenos analisados.

A pesquisa tem como objetivo geral identificar e discutir a influência do movimento OA nas comunidades acadêmicas da área de Biblioteconomia das Universidades Federais da Região Nordeste do Brasil, nomeadamente nas Universidades Federais da Bahia, Paraíba, de Alagoas, de Pernambuco, do Ceará, do Rio Grande do Norte e do Maranhão, com ênfase sobre as questões relativas à "via verde" e à "via dourada", com a finalidade de responder a seguinte questão: Que efeitos/consequências a "via verde" e a "via dourada" de disseminação da informação trazem para a comunicação científica nas comunidades acadêmicas da área de Biblioteconomia da Região Nordeste do Brasil?

Os objetivos específicos são:

- Estabelecer um paralelo entre as duas estratégicas básicas, definidas em Budapeste, sendo a primeira estratégia o autoarquivamento, que constitui a via verde (Green Road) - e a segunda estratégia os periódicos eletrônicos de acesso aberto, que constituem a via dourada (Golden Road);

- Verificar a importância da utilização das vias verde e dourada para a disseminação da informação, como uma alternativa aos mecanismos tradicionais de comunicação científica no meio acadêmico;

- Relacionar a diferença entre legitimação e legitimidade das publicações eletrônicas de acesso aberto, com o uso da via verde e da via dourada; 
- Discutir a importância da Open Archives Initiative (OAI) na implementação do movimento do OA.

Um dos primeiros passos na estruturação do projeto de pesquisa foi a elaboração do modelo de análise, que estabeleceu os parâmetros para a realização dessa pesquisa, determinando o que se queria investigar. Assim, este procedimento envolveu o conceito de comunicação científica que, segundo Garvey e Grifith (1979 apud LEITE; COSTA, 2006, p. 207), compreende o conjunto de todas as atividades que englobam a produção, a disseminação e o uso da informação desde o início do processo de criação científica, segundo o qual as ideias da pesquisa são geradas até ao momento da aceitação dos resultados como parte do corpo de conhecimento científico. Os componentes foram consultados e selecionados de acordo com a Plataforma Lattes/Currículos Lattes, tal como apresentado no Quadro1.

\section{Quadro 1 - Modelo de análise}

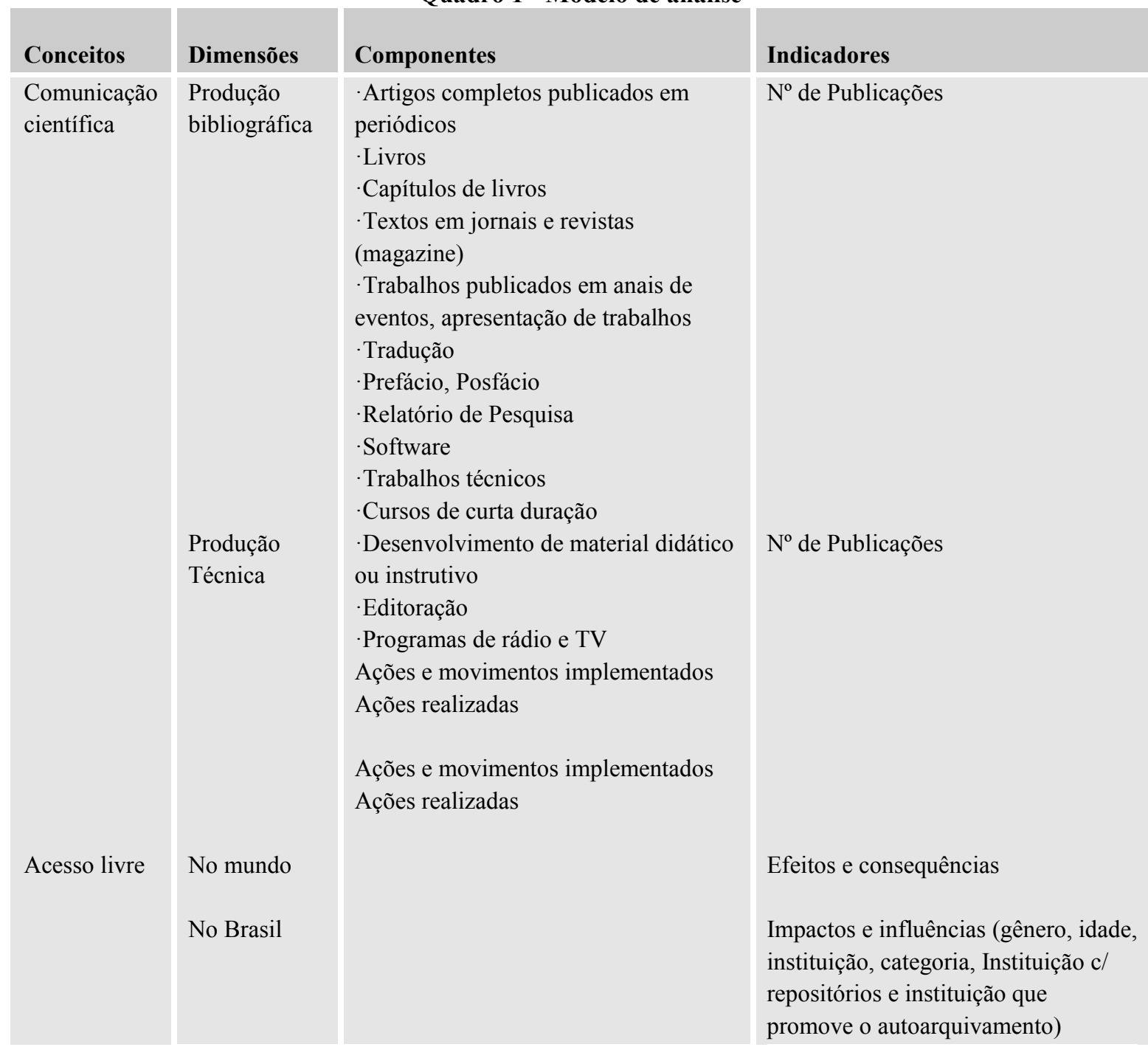


O modelo de análise, constituído a partir dos conceitos básicos utilizados no início da elaboração do projeto de pesquisa, trata da comunicação científica e do acesso livre (sem restrições) à comunicação científica. Ao longo deste trabalho, utilizamos duas dimensões para o conceito de comunicação científica: (1) produção bibliográfica, que envolve os trabalhos publicados, como por exemplo: artigos completos publicados em periódicos, livros, capítulos de livros, textos em jornais e revistas (magazine), trabalhos publicados em anais de eventos, apresentação de trabalhos, traduções, prefácios, posfácios, relatórios de pesquisa, que aqui são utilizados como componentes da dimensão bibliográfica e, por sua vez, o número de publicações foi utilizado como indicador, com a finalidade de verificar a produção bibliográfica em acesso livre; (2) produção técnica, que envolve a criação de software, trabalhos técnicos, cursos de curta duração, desenvolvimento de material didático ou instrucional, editoração, programas de rádio e TV, aqui utilizados como componentes da dimensão produção técnica, e os números da respectiva publicação funcionaram como indicadores.

O conceito de acesso livre à comunicação científica possui duas dimensões: (1) no mundo e como componente, utilizamos as ações e movimentos implementados em prol do acesso livre à informação científica, e, como indicador, utilizamos os efeitos e/ou consequências dessas ações sobre o acesso livre à informação científica; (2) no Brasil, como componente, usamos ações realizadas no país em favor do acesso livre à informação científica e, como indicadores, os impactos ou influências dessas ações sobre o acesso livre a informação científica, levando em consideração o gênero, a idade, a instituição onde os entrevistados lecionam ou estudam, a categoria que ocupam na carreira de docente, se a instituição onde trabalham ou estudam possui repositórios e se estas promovem o autoarquivamento.

Os conceitos, as dimensões, os componentes e os indicadores apresentados no Quadro1 nortearam a estruturação e o desenvolvimento do corpo da pesquisa.

Utilizamos, como instrumentos de coleta de dados, de acordo com Bruyne et al. (apud Lessard-Héberd et al. 1990, p. 143), o inquérito de forma oral - entrevista orientada para informação que pretendeu circunscrever a percepção e o ponto de vista de uma pessoa ou de um grupo de pessoas em uma determinada situação, que foi aplicada, neste caso, ao tecnologista sênior do IBICT com a finalidade de obter informações sobre o movimento OA no Brasil - e o inquérito de forma escrita: o questionário conforme o apresentam Powney e Watts (1987 apud Lessard-Héberd et al. 1990, p. 162), aplicado aos professores e aos alunos 69

Enc. Bibli: R. Eletr. Bib. Ci. Inf., ISSN 1518-2924, Florianópolis, , v. 17, n. esp. 2 - III SBBC, p. 65-81, 2012. 
dos cursos de Biblioteconomia com o objetivo de verificar os efeitos e as consequências do movimento OA sobre as comunidades acadêmicas da área de biblioteconomia das Universidades Federais da Região Nordeste do Brasil, localizadas na Bahia, Alagoas, Pernambuco, Paraíba, Rio Grande do Norte, Ceará e Maranhão.

Para a realização da pesquisa foram elaborados dois questionários, um para os estudantes e outro para os professores. O questionário dos estudantes continha trinta e duas questões, divididas em quatro partes: a primeira parte tinha a finalidade de recolher dados pessoais e institucionais do aluno; a segunda parte possuía o objetivo averiguar conhecimento sobre o OA; a terceira parte tinha como intuito verificar a sua produção bibliográfica em OA; e a quarta parte possuía o propósito de verificar a sua produção técnica em OA. Os questionários foram enviados aos estudantes por três vezes em virtude das várias dificuldades encontradas na obtenção das listas de e-mails dos alunos dos cursos de Biblioteconomia por meio das Coordenações de Cursos ou mesmo dos Centros Acadêmicos. Como essas listas não existiam, isso impediu a participação dos alunos do Curso de Biblioteconomia da Universidade Federal da Bahia (UFBA) na pesquisa. Outra questão bastante relevante foi o reduzido número de e-mail de alunos fornecidos pelo Centro Acadêmico ou mesmo pelas Coordenações dos Cursos e o longo tempo de espera entre o pedido das listas de e-mail e o fornecimento destas. Ainda neste contexto, existiu, concomitantemente, um grande número de e-mails que retornaram à caixa de mensagens, face à inexatidão da informação relativa à lista de e-mails. Esse fato verificou-se frequentemente durante o envio dos referidos e-mails para os alunos. De acordo com a Tabela 1, abaixo apresentada, pode-se verificar o número de alunos e os questionários recebidos.

Tabela 1: Número de alunos e questionários recebidos

\begin{tabular}{|l|c|c|c|}
\hline $\begin{array}{c}\text { Universidades } \\
\text { Federais }\end{array}$ & $\begin{array}{c}\mathbf{N}^{\mathbf{0}} \text { de } \\
\text { alunos }\end{array}$ & $\begin{array}{c}\text { Frequência } \\
\mathbf{( N )}\end{array}$ & $\begin{array}{c}\text { Percentual } \\
\text { por } \\
\text { universidade }\end{array}$ \\
\hline UFAL & 124 & 42 & $\mathbf{3 3 , 8}$ \\
\hline UFC & 142 & 46 & 32,3 \\
\hline UFRN & 150 & 21 & 14,0 \\
\hline UFPB & 448 & 22 & 4,9 \\
\hline UFPE & 192 & 4 & 2,0 \\
\hline UFMA & 325 & 2 & 0,6 \\
\hline UFBA * & 242 & 0 & 0 \\
\hline
\end{tabular}

participaram da pesquisa porque não obtivemos a lista de e-mails dos referidos alunos. E mais oito alunos não informaram suas instituições. 
Um segundo questionário foi elaborado para os professores, contendo trinta e quatro questões organizadas em quatro partes distintas: a primeira parte, com a finalidade de recolher dados pessoais e institucionais do professor; a segunda parte, com a intenção de verificar conhecimento sobre o OA; a terceira parte, com o objetivo de verificar a sua produção bibliográfica em OA; e quarta parte para verificar a sua produção técnica em OA. Os questionários dirigidos aos professores foram enviados por duas vezes, em situação semelhante a dos questionários dos alunos. De acordo com a Tabela 2, abaixo apresentada, pode-se verificar o número de professores e os questionários recebidos.

Tabela 2: Número de professores e questionários recebidos

\begin{tabular}{|l|c|c|c|}
\hline $\begin{array}{c}\text { Universidades } \\
\text { Federais }\end{array}$ & $\begin{array}{c}\mathbf{N}^{\mathbf{0}} \text { de } \\
\text { professores }\end{array}$ & $\begin{array}{c}\text { Frequência } \\
\mathbf{( N )}\end{array}$ & $\begin{array}{c}\text { Percentual } \\
\text { por } \\
\text { Universidade }\end{array}$ \\
\hline UFAL & 10 & 9 & $\mathbf{9 0 . 0}$ \\
\hline UFRN & 14 & 6 & 42,8 \\
\hline UFPB & 24 & 10 & 41,6 \\
\hline UFBA & 25 & 9 & 36,0 \\
\hline UFC & 18 & 6 & 33,3 \\
\hline UFPE & 17 & 5 & 29,4 \\
\hline UFMA & 23 & 4 & 17,3 \\
\hline
\end{tabular}

Dois dos professores respondentes não indicaram qual a instituição onde trabalham.

Para analisar os dados recolhidos, foi utilizado o programa SPSS, com o objetivo de facilitar a mensuração das informações recebidas, a construção de tabelas, privilegiando sempre a frequência e o percentual válido.

\section{DISCUSSÃO E RESULTADOS}

A crise no setor dos periódicos, de acordo com Moraes (2006, p. 25), foi marcada por fatores, como: a) a fusão das editoras comerciais; b) o aumento dos preços das revistas, que em pouco tempo abalou a continuidade das assinaturas, levando muitas bibliotecas a excluírem vários títulos; c) as vendas de assinaturas por pacotes, com diminuição de custos, nos quais eram incluídas revistas que não interessavam às bibliotecas, as quais passaram, inclusive, a ter títulos que antes não podiam pagar; d) consórcios de bibliotecas para auxiliar na negociação com as grandes editoras - as bibliotecas se agregaram em consórcio para 71

Enc. Bibli: R. Eletr. Bib. Ci. Inf., ISSN 1518-2924, Florianópolis, , v. 17, n. esp. 2 - III SBBC, p. 65-81, 2012. 
comprar material científico e disponibilizá-lo ao usuário por meio de intercâmbio ou pela Comutação Bibliográfica (COMUT). Toda essa situação foi agravada pela inexistência de concorrência, o que monopolizou o mercado, deixando as instituições sem opção, porque a “ciência não existe sem comunicação" (MORAES, 2006, p. 25) e o público consumidor é certo. No Brasil, foi criado um dos mais importantes consórcios, o Portal de Periódicos CAPES da Coordenação de Aperfeiçoamento de Pessoal de Nível Superior (CAPES), por meio de uma iniciativa federal.

De acordo com Sena (2006, p. 72), torna-se evidente a discrepância entre a morosidade do processo da comunicação científica tradicional e a rapidez com que algumas áreas do conhecimento se desenvolvem e promovem a divulgação de seus trabalhos. Nesse contexto, surge a questão da transferência dos direitos autorais para os editores, o que nem sempre atende aos interesses dos autores. Além disso, a importância do processo de revisão feita pelos autores e o tempo despendido limita o processo de disseminação de novas ideias, facilitando a promoção de grupos restritos de editores e autores. Segundo Jacobs (2006, p. 1), as preocupações relativas ao tenso sistema de comunicação acadêmica levaram à proliferação de um movimento para a mudança.

Se houve um tempo em que editores científicos tiveram um papel incontornável na divulgação do conhecimento, constitui hoje, pela total arbitrariedade de custos dos títulos que oferecem, os principais obstáculos a essa mesma difusão que resulta da incapacidade de suportes pelas instituições e respectivas bibliotecas (BORGES, 2006, p. 72).

De acordo com Correia (2001 apud FERREIRA; MODESTO; WEITZEL, 2004 p. 196), o controle de qualidade das publicações, realizado por meio da revisão feita pelos pares, vem sendo criticado pela comunidade científica, apesar de ser importante para o desenvolvimento da ciência. Entre as principais críticas, salientam-se:a) a insatisfação em relação à falta de agilidade e velocidade no processo; b) o excesso de rigidez no processo, que funciona mais como "repressor" ou mesmo "supressor" do aparecimento de novas idéias do que como fomento; c) $\mathrm{O}$ favorecimento de publicação de artigos de autores inseridos em instituições prestigiadas em detrimento dos demais autores, que podem criar atrasos indesejáveis na publicação de resultados de investigações originais.

Segundo Bailey (2006), para aprofundar o conhecimento, os investigadores necessitam acessar a literatura científica relevante. Cada vez mais essa literatura é interdisciplinar, global, dispendiosa, digital e é escondida por trás de barreiras técnicas para cumprir as restrições de licenciamento. E até mesmo os pesquisadores de importantes universidades em todo o mundo têm dificuldade em acessar a literatura especializada. 
O movimento do acesso livre acredita ter a resposta para essa questão crítica. Os líderes desse movimento não estão tão interessados em reformar o sistema de comunicação investigacional já existente, mas sim em transformá-lo para que possa funcionar com eficácia num ambiente tecnológico em rápida mudança.

As pesquisas científicas, na sua maioria, são financiadas pelo Estado; são realizadas por meio do recurso a fundos públicos. Logo, os resultados dessas pesquisas deveriam ser de livre acesso. Mas não é essa a situação que ocorre no sistema de comunicação científica tradicional, pois o pesquisador ou qualquer outro cidadão, para ter acesso ao que foi financiado com o apoio do Estado, precisará pagar pela assinatura de uma publicação científica. O Estado, por sua vez, para promover o acesso àquilo que produz, é obrigado a arcar com os custos de manutenção das coleções e das revistas, nas quais são publicados os resultados da sua própria produção científica.

Para Wilinsks (2006), é tempo de fazer uma mudança radical na forma como a informação está sendo disponibilizada, particularmente a informação científica, que resulta de investigação pública e é financiada por instituições de fomento ou órgãos governamentais. $\mathrm{O}$ autor supracitado alerta, ainda, para o fato de que cada vez mais a informação torna-se menos acessível devido a práticas de publicação retrógradas, contudo, a longo prazo, essa forma de disseminação ou publicação poderá alterar-se.

De acordo com Borges (2006, p. 81) o movimento do acesso livre começou em 1994, quando Stevan Harnad dá início a sua proposta "subversiva" numa lista de discussão disponível na internet dedicada ao tema das revistas eletrônicas (OKERSON; O’ DONNEL, 1995 apud BORGES, 2006). Na resposta a essa proposta, esteve presente Paul Ginsparg, o criador do arquivo de Los Alamos, atualmente conhecido por Arxiv, um arquivo de preprints na área da física e da alta energia, cujo sucesso ampliou os horizontes na partilha da informação científica.

Sem se limitarem apenas às instituições de ensino superior, mas de um modo amplo, Paul Ginsparg, Rick Luce e Herbert Van de Sompel, em 1999, realizaram uma reunião com especialistas para preparar um documento com as recomendações da Convenção de Santa Fé, a qual tinha o objetivo de estimular a discussão sobre as normas a serem estabelecidas para o desenvolvimento de um serviço internacional de autoarquivamento, por parte dos pesquisadores.

Para Baptista, Costa, Kuramoto e Rodrigues (2007, p. 9), a Convenção de Santa Fé determinou as especificações técnicas e os princípios administrativos necessários para se criar 73

Enc. Bibli: R. Eletr. Bib. Ci. Inf., ISSN 1518-2924, Florianópolis, , v. 17, n. esp. 2 - III SBBC, p. 65-81, 2012. 
um alto nível de interoperabilidade funcional entre repositórios. Sendo essenciais: o mecanismo de submissão; o sistema de armazenamento a longo prazo; uma política de gestão para a submissão e preservação de documentos; e uma interface aberta que permita a terceiros coletar os metadados dos respectivos arquivos componentes indispensáveis para um arquivo de e-prints.

Segundo Ferreira, Modesto e Weitzel (2004 p. 198), a Convenção de Santa Fé fundamenta-se num conjunto de acordos simples que estabelecem princípios organizacionais e de especificações técnicas, mas que possibilitam um elevado grau de interoperabilidade entre os vários arquivos de eprints, além de formar uma nova filosofia para a publicação científica, qual seja: o autoarquivamento de trabalhos e a revisão dos trabalhos (peer review) pela própria comunidade científica de pesquisadores, "favorecendo um modelo mais eqüitativo e eficiente para a disseminação dos resultados de pesquisa e abrindo o círculo restrito de editores e autores inerentes ao sistema de publicações periódicas" (DAVIS et al., 2002 apud FERREIRA; MODESTO; WEITZEL, 2004, p. 198).

A Budapest Open Access Initiative também é conhecida como BOAI. A sigla em língua inglesa surgiu numa reunião promovida pelo Open Society Institute (OSI) em dezembro de 2001, que contou com a presença de vários acadêmicos, bibliotecários e outras personalidades ligadas ao sistema de comunicação científica. A reunião teve como objetivo acelerar o progresso do esforço internacional que busca tornar os artigos científicos de todas as áreas acadêmicas disponíveis na internet.

Durante a reunião BOAI foi estabelecido um conceito para Acesso Livre. A definição de Acesso Livre, segundo Bailey (2006), continua bastante influente e atual:

A literatura que devia estar livremente disponível online é a que os pesquisadores dão ao mundo sem receberem dinheiro em troca. À primeira vista, esta categoria inclui os artigos de periódicos revistos pelos pares, mas também inclui as pré-impressões não revistas pelos pares que podem colocar online para serem comentados ou para alertar os pesquisadores para importantes resultados de determinadas pesquisas.

A BOAI 2002 resultou da reunião promovida pelo OSI em dezembro de 2001. Em consonância com os parâmetros defendidos por Costa (2006, p. 41), a BOAI, em 2002, definiu duas estratégias básicas, apoiadas no uso do Protocolo OAI-PMH. A primeira estratégia é a de autoarquivamento (via verde). A segunda estratégia trata da via dourada (golden road).

De acordo com Rodrigues (2006), o Acesso Livre não é direcionado para os livros com os quais os autores pretendam conseguir rendimentos ou receitas, tampouco para textos 
não acadêmicos, como notícias ou ficção. O Acesso Livre pode, então, ser utilizado para os trabalhos em que os autores não esperam recompensas financeiras, como exemplo: comunicações, conferências e congressos, teses e dissertações, relatórios técnicos, working papers, relatórios governamentais etc.

Existe uma multiplicidade de definições do que vem a ser Acesso Livre, mas o "Acesso Livre diz respeito à acessibilidade ampla e irrestrita a conteúdos disponíveis em formato digital, no sentido em que remove barreiras de preço e de permissão, tornando a literatura científica disponível com o mínimo de restrições de uso" (SUBER 2003 apud BATISTA; COSTA; KURAMOTO; RODRIGUES 2007, p. 5).

Para Mueller (2006, p. 1), o movimento para o acesso livre ao conhecimento científico pode ser considerado o evento mais significativo da nossa época no que se refere à comunicação científica e, nesse sentido, torna-se um grande desafio para a comunidade acadêmica. Quanto mais sucesso obtiver o movimento, maior será o impacto sobre as mudanças provocadas no sistema tradicional.

A reunião de Bethesda (2003) teve como intenção reunir, em poucos meses, um amplo grupo de trabalho para elaborar um conjunto de princípios - três declarações compostas pelos grupos de trabalho das instituições de pesquisa; grupos de trabalho dos bibliotecários e editores e grupo de trabalho dos pesquisadores e sociedades científica; e uma definição para publicação de acesso aberto. A partir dessa definição são direcionados os debates e decisões que estão mudando o cenário da comunicação científica. Assim, fica estabelecido, como informa Costa (2006, p. 42), que as publicações de acesso aberto devem preencher duas condições:a primeira é que autores e detentores de direitos autorais devem assegurar a todo usuário: direito livre, irrevogável e perpétuo de acesso a seus trabalhos; e a segunda é que uma versão completa do trabalho publicado, assim como de todo material suplementar, incluindo uma cópia da permissão citada na primeira condição, em formato eletrônico apropriado, devem ser depositadas, imediatamente após a publicação inicial, em pelo menos um repositório on-line.

O conceito estabelecido em Bethesda confirma o que foi proposto em Budapeste, envolvendo as agências de fomento, os cientistas, os editores, os próprios pesquisadores e os bibliotecários.

A reunião intitulada Berlin Declaration Open Access to Knowledge in the Science and Humanities visou eleger a internet como "instrumento funcional para uma base global de conhecimento científico e reflexão humana" e estabelecer as medidas que precisam de ser 75

Enc. Bibli: R. Eletr. Bib. Ci. Inf., ISSN 1518-2924, Florianópolis, , v. 17, n. esp. 2 - III SBBC, p. 65-81, 2012. 
consideradas entre os formuladores de política, instituições de pesquisa, agências de fomento, bibliotecas e museus. Com a finalidade de endossar a Declaração de Berlim, as instituições devem:

\footnotetext{
- implementar uma política para requerer de seus pesquisadores que depositem em um repositório de acesso aberto uma cópia de todos os seus artigos publicados;

- encorajar seus pesquisadores a publicar seus artigos de pesquisa em periódicos de acesso aberto - onde haja um periódico apropriado - e prover o apoio necessário para que isso aconteça (COSTA, 2006, p. 43).
}

O modelo OA possibilita a disponibilização de textos científicos completos através da internet, sejam eles: teses, artigos de periódicos, trabalhos apresentados em congressos, literatura cinzenta, que se tornam cada vez mais visíveis com a utilização desse modelo.

A partir de 2005, com a elaboração Manifesto Brasileiro de apoio ao Acesso Livre à Informação Científica, e segundo Kuramoto (2008), o Brasil vem realizando,por meiodo IBICT, várias inciativas em favor desse movimento, entre as quais pode-se mencionar: a assinatura da Declaração de Berlim (2003); a submissão, a aprovação e o desenvolvimento do Projeto de Publicações Periódicas de Acesso Livre (PCAL) junto a Financiadora de Estudos e Projetos (FINEP); a prospecção, a identificação, a absorção, a customização, o aperfeiçoamento e a distribuição de tecnologias para o tratamento e disseminação da informação, que dão suporte às ações de acesso livre, a exemplo do Sistema Eletrônico de Editoração de Revistas (SEER); a construção de repositórios institucionais (RI) e temáticos de acesso livre; o Projeto de Lei 1120/2007 e o Projeto de Lei 387/2011-que dispõe sobre o processo de registro e disseminação da produção técnico-científica pelas instituições de educação superior, bem como as unidades de pesquisa no Brasil e dá outras providências; a implantação da Biblioteca Digital Brasileira de Teses e Dissertações (BDTD). Para além destas iniciativas, foram publicados, em 2006, um número especial da revista Ciência da Informação (35:2), e, em 2008, da Revista LIINC (4:2), ambas com artigos de pesquisadores brasileiros e estrangeiros sobre o tema do acesso livre.

Além das iniciativas acima citadas, outras declarações de apoio ao OA vêm sendo elaboradas por instituições e/ou associações acadêmicas em várias partes do Brasil, como a Declaração de Salvador (2005), a Carta de São Paulo (2005), a Carta de Florionópolis (2006), a Carta aberta elaborada durante a 58 reunião anual da Sociedade Brasileira para o Progresso da Ciência (2006), a Carta do Rio de janeiro (2007) e a Carta de Apoio ao Acesso Aberto à Produção Técnico-Científica, Artística e Didática da Universidade de São Paulo (2010). 
A pesquisa realizada procurou identificar os efeitos e/ou as consequências desse movimento sobre a comunidade acadêmica da área de Biblioteconomia na Região Nordeste do Brasil.

Verificamos que a maioria dos professores respondentes $(67,3 \%)$ informou que a universidade onde trabalha possui repositório institucional.

\begin{tabular}{|l|c|c|}
\hline $\begin{array}{c}\text { A universidade onde trabalha possui } \\
\text { repositório institucional }\end{array}$ & $\begin{array}{c}\text { Frequência } \\
\text { (N) }\end{array}$ & $\begin{array}{c}\text { Percentual } \\
\mathbf{( \% )}\end{array}$ \\
\hline Sim & 33 & $\mathbf{6 7 , 3}$ \\
\hline Não & 16 & 32,7 \\
\hline
\end{tabular}

A maior parte dos professores respondentes possui produção bibliográfica em OA (74,3\%). De fato, os docentes respondentes possuem um elevado número de publicações em OA.

\begin{tabular}{|l|c|c|}
\hline \begin{tabular}{|l|l|} 
Possui produção bibliográfica em \\
OA
\end{tabular} & $\begin{array}{c}\text { Frequência } \\
(\mathbf{N})\end{array}$ & $\begin{array}{c}\text { Percentual } \\
\mathbf{( \% )}\end{array}$ \\
\hline Sim & 26 & $\mathbf{7 4 , 3}$ \\
\hline Não & 9 & 25,7 \\
\hline
\end{tabular}

A maioria dos professores respondentes $(90,0 \%)$ utiliza produção bibliográfica em OA para realização de seus trabalhos acadêmicos.

\begin{tabular}{|c|c|c|}
\hline $\begin{array}{c}\text { Utiliza produção } \\
\text { bibliográfica em OA }\end{array}$ & $\begin{array}{c}\text { Frequência } \\
(\mathbf{N})\end{array}$ & $\begin{array}{c}\text { Percentual } \\
(\mathbf{\%})\end{array}$ \\
\hline Sim & 36 & $\mathbf{9 0 , 0}$ \\
\hline Não & 4 & 10,0 \\
\hline
\end{tabular}

Foi possível verificar que $62,8 \%$ das universidades onde os alunos respondentes estudam possuem repositórios institucionais e que apenas 37,2\% não possuem repositórios. 


\begin{tabular}{|c|c|c|}
$\begin{array}{c}\text { A universidade onde estuda } \\
\text { possui repositório institucional }\end{array}$ & $\begin{array}{c}\text { Freqüência } \\
\text { (N) }\end{array}$ & $\begin{array}{c}\text { Percentual } \\
\mathbf{( \% )}\end{array}$ \\
\hline Sim & 86 & $\mathbf{6 2 , 8}$ \\
\hline Não & 51 & 37,2 \\
\hline
\end{tabular}

A maioria dos alunos respondentes $(78,6 \%)$ informou que não possui produção bibliográfica em OA e apenas uma minoria dos alunos respondentes $(21,4 \%)$ informou que possuí.

\begin{tabular}{|l|c|c|}
\hline Possui produção bibliográfica em OA & $\begin{array}{c}\text { Freqüência } \\
\text { (N) }\end{array}$ & $\begin{array}{c}\text { Percentual } \\
(\mathbf{\%})\end{array}$ \\
\hline Sim & 6 & 21,4 \\
\hline Não & 22 & $\mathbf{7 8 , 6}$ \\
\hline
\end{tabular}

$87,5 \%$ dos alunos respondentes, assim como 90,0\% dos professores respondentes, afirmaram que utilizam produção bibliográfica em OA como fonte de pesquisa.

\begin{tabular}{|c|c|c|}
\hline $\begin{array}{c}\text { Utiliza produção } \\
\text { bibliográfica em OA }\end{array}$ & $\begin{array}{c}\text { Freqüência } \\
\text { (N) }\end{array}$ & $\begin{array}{c}\text { Percentual } \\
(\mathbf{\%})\end{array}$ \\
\hline Sim & 28 & $\mathbf{8 7 , 5}$ \\
\hline Não & 4 & 12,5 \\
\hline
\end{tabular}

A realização dessa pesquisa permitiu adquirir informações sobre o movimento OA no mundo e, de uma forma especial, no Brasil:

- Como fator bastante positivo para o movimento do OA no Brasil, a maior parte das Universidades inquiridas possui RI;

- Apesar de a maioria das universidades da região inquirida possuir RI, ainda é significativamente baixo o número de produção bibliográfica de docentes e principalmente de discentes, depositada nesses repositórios;

- A maioria dos professores e alunos respondentes utiliza produção bibliográfica em OA nos seus mais variados tipos, sobretudo artigos publicados em periódicos eletrônicos em $\mathrm{OA}$, mas só os docentes possuem um número significativo de produção bibliográfica publicada em OA. 
Como verificamos a partir da revisão de literatura e dos resultados dos inquéritos aplicados, podemos afirmar que a comunidade acadêmica da área de Biblioteconomia na Região Nordeste do Brasil concorda e aceita o acesso livre, já sendo visível o impacto ou a influência do movimento do acesso livre no país e, especificamente, nessa Região.

Recomenda-se continuar a investir na divulgação do movimento em prol do acesso livre e a implementar programas e projetos, de forma a ampliar e estimular a utilização do autoarquivamento (via verde) e a criação de periódicos de acesso livre (via dourada). Esse impulso não deverá ser proporcionado só por meio doGoverno brasileiro ou do IBCT, mas também por meio do envolvimento direto das próprias comunidades acadêmicas com os seus pares, nas suas instituições, para que o acesso livre se torne de fato uma alternativa para a disseminação do conhecimento científico e para que o Brasil e especificamente a Região Nordeste tenham a possibilidade de aumentar a visibilidade da sua produção científica no Brasil e no mundo. 


\section{REFERÊNCIAS}

BAILEY, Charles Jr. What is open access? In: Open Access: Key Strategic, Technical and Economic Aspects. England: Chandos Publishing, 2006. p. 13-26.

BATISTA, Ana Alice; COSTA, Sely M. de S.; KURAMOTO, Hélio; RODRIGUES, Eloy. Comunicação científica: o papel da Open Archives Initiative no contexto do Acesso Livre. Encontros Bibli: Revista Eletrônica Biblioteconomia e Ciência da Informação, Florianópolis, $1^{\circ}$ sem. $\quad$ p. $5-17, \quad 2007 . \quad$ Disponivel em: $<$ http://repositorium.sdum.uminho.pt/bitstream/1822/8727/1/2007EncontrosBibli.pdf $>$.

Acesso em: 11 nov. 2010.

BERLIN DECLARATION OPEN ACCESS TO KNOWLEDGE IN THE SCIENCE AND HUMANITIES. Berlin, 2003. Disponível em: <http://oa.mpg.de/openaccessberlin/berlindeclaration.html>. Acesso em: 29 mar. 2009.

BETHESDA STATEMENT ON OPEN ACCESS PUBLISHING. Bethesda, 2003. Disponível em: <http://www.earlham.edu/ peters/fos/bethesda.htm>. Acesso em: 31 mar. 2009.

BORGES, Maria Manuel. A esfera: comunicação acadêmica e novos media. Coimbra, 2006. CDROM.

BUDAPEST OPEN ACCESS INITIATIVE - BOAI. Hungary (Budapest), 2001.

Disponível em: <http://www.soros.org/openaccess> Acesso em: 20 mar. 2010. 1025.

BUDAPEST OPEN ACCESS INITIATIVE - BOAI.Hungary (Budapest), 2002.

Disponível em: <http://www.soros.org/openaccess/read.shtml>. Acesso em: 31 mar. 2009. $10: 15$.

COSTA, Sely M.S. Filosofia aberta, modelo de negócios e agências de fomento: elementos essenciais a uma discussão sobre o acesso aberto à informação cientifica. Ci. Inf., Brasília, v.35. n.2, p. 39-50, maio/ago. 2006.

Disponível em: $<$ http://revista.ibict.br/ciinf/index.php/ciinf/article/view/827/670>. Acesso em: 6 maio 2010

FERREIRA, Sueli Maras. S.P.; MODESTO, Fernando; WEITZEL, Simone da Rocha. Comunicação científica e o protocolo OAI: uma proposta na área das Ciências da Comunicação.Comunicação e Sociedade, Braga, v. 6, p. 193-209, 2004.

JACOBS, Neil. Open access: key strategic, technical and economic aspects. England: ChandosPublishing, 2006. 243p.

LEITE, Fernado Cesar Lima; COSTA, Suely. Repositórios institucionais como ferramentas de gestão do conhecimento científico no ambiente acadêmico. Perspect. Ciênc. inf., Belo Horizonte, v.11,n.2, p. 206-219, mai./ago. 2006.

Disponível em: <http://www.scielo.br/pdf/\%0D/pci/v11n2/v11n2a05.pdf>. Acesso em: 15 de mar. 2011.

KURAMOTO, Helio. Acesso livre à informação científica: novos desafios. Liinc em Revista. Rio de Janeiro, v.4, n.2. 2008. 
Disponível em: <http://www.ibict.br/liinc> . Acesso em: 12 set. 2009.

LESSARD, Hebert, M.; Gabriel G., Gerald B. Investigação qualitativa: Fundamentos e Práticas. Lisboa: Instituto Piaget, 1900.

MORAES, Rosana Portugal Tavares de. O "livre acesso" e os "arquivos abertos" na comunicação cientifica. Niterói: [s.n.], 2006. 59p.

Disponível em:

$<$ http://dici.ibict.br/archive/00001150/01/Monografia_Rosana_Portugal.pdf $>$.Acesso em: 25 out. 2010. 16:21.

MUELLER, Suzana Pinheiro Machado - A comunicação científica e o movimento de acesso livre ao conhecimento. Ciência da Informação. Brasília, v. 35, n.2, p. 27-38 maio - ago., 2006.

Disponível em: <http://www.scielo.br/pdf/ci/v35n2/a04v35n2.pdf>. Acesso em: 30 out. 2006.

RODRIGUES, Eloy. Acesso Livre: Utopia ou realidades. IN:ENCONTRO NACIONAL DE BIBLIOTECAS JURÍDICAS, 1, 2004, Lisboa, Direito e informação: actas...Coimbra: Coimbra Editora, 2006. ISSN 0870-3116.p.29-40.

Disponível em: <http://repositorium.sdum.uminho.pt/handle/1822/4942>. Acesso em: 12.dez. 2009.

SENA, Nathália K. Open Archives: o caminho alternativo para comunicação científíca. Ciência da Informação. Brasília, v. 29, n. 30, p. 71-78. set./dez. 2006. Disponível em: $<$ http://www.scielo.br/scielo.php?script=sci_arttext\&pid=S0100196520000003007>.Acesso em: 30 out. 2010.

WILLINSKY, John. The access principle: the case for open access to research and scholarship. Cambridge, MA: Massachusetts Institute of Technology. 2006. 287 p. 